\title{
Towards a smart city through household recycling and waste management: a study on the factors affecting environmental friendliness lifestyle of Guamanian
}

\author{
Kevin K.W. Ho \\ The University of Guam, \\ School of Business and Public Administration, \\ SBPA Bldg. Rm. 227, Guam, USA \\ Email: kevinkho@uguam.uog.edu
}

\section{Stuart So*}

The Hong Kong Polytechnic University, Institute of Textile and Clothing,

Hung Hum, Hong Kong

Email: stuart.ck.so@gmail.com

*Corresponding author

\begin{abstract}
Cities that can improve their environmental performance will benefit from having a healthier, more productive populace that enjoys a better quality of life. This study attempts to answer the question of how to create a 'smart' sustainable city through developing a culture of sustainability from a waste management perspective. With this concept in mind, a waste reduction model is theorised. The model is tested with the data obtained from Guam with the aim of helping Guamanian develop better environmental friendlier lifestyle. The results show that the more users reach the media with sustainability message, the more impact on their pro-environmental behaviour. It is suggested that the Guam authority should better utilise the media to educate the public such as designing a better media campaign to promote environmentally friendly custom.
\end{abstract}

Keywords: Hofstede cultural dimensions; Guam; smart cities; sustainability; waste management.

Reference to this paper should be made as follows: Ho, K.K.W. and So, S. (2017) 'Towards a smart city through household recycling and waste management: a study on the factors affecting environmental friendliness lifestyle of Guamanian', Int. J. Sustainable Real Estate and Construction Economics, Vol. 1, No. 1, pp.89-108.

Biographical notes: Stuart So is a Research Fellow at the Hong Kong Polytechnic University. He received his Doctorate from Macquarie University and completed his Research Fellowship at City University of Hong Kong. His research interests include sustainability, supply chain and operations management, lean thinking, entrepreneurship and innovations. 
Kevin K.W. Ho is an Associate Professor of Management Information Systems at the University of Guam. His research interests include electronic service, information systems strategy, sustainability management, and electronic government. He has published in Computers in Human Behaviour, Decision Support Systems, Information and Management, etc.

This paper is a revised and expanded version of a paper entitled 'Towards a smart city through household recycling and waste management: A study on the factors affecting environmental friendliness lifestyle of Guamanian' presented at First Young Researchers Workshop on 'Smart Cities for Sustainable Development', Hong Kong, 22 January 2016.

\section{Introduction}

Guam is an unincorporated territory of the USA, which is located in the Western Pacific and is within 5-hour flight from most of the major cities in the Asia Pacific, such as Hong Kong, Taipei, Tokyo, and Seoul, etc. It is famous for its tourist attractions, as well as its military bases (including one air force base in the north, and one naval base in the south of the island). Its population is around 167,500 (The World Bank, 2014a) and its tourism industry served over 1.34 million visitors (Ruane, 2015) in 2014. It is anticipated that the military and their dependents moving located at the US military bases in Okinawa, Japan, will move to Guam in the coming decade based on the agreement between the US and the Japanese Governments (Owen, 2010), which means that the population of the island will increase significantly. Plus, the Guam Visitors Bureau (2014) also has a vision that there will be 2 million people visiting Guam per year by 2020. Obviously, this will create a pressure for the Government of Guam (GovGuam) for improving the existing infrastructure of Guam to cater for the growth of the population.

To cope with the needs for (re)developing the island infrastructure to cater for the impacts of the military build-up and the anticipation of the increase of the number of visitors, the GovGuam has launched a major project, Imagine Guam, in 2015. In brief, the Imagine Guam (2016) is a 50-year plan for the island of Guam, which kicks off with an in-depth Delphi study (Helmer, 1967) for developing the blueprint for a sustainable development of Guam in the next five decades, which aims to pave the way for Guam to becoming as a 'smart' island, which can be self-sustainable.

To (re)develop Guam to become a smart island which can be self-sustainable, we can draw reference from the concept of a sustainable city as Guam is conceptually equivalent to a city occupying an island of 212 square miles. The World Bank (2014b) characterises a sustainable city that encourages economic growth actually facilitating climate resilience, in which waste management is a key item on its sustainable development agenda to improve the livelihoods. Fundamentally, smart cities use technology and process innovation to improve the quality of life for all stakeholders within a community. As stated earlier, as Guam is anticipating a huge increase in population, to cope with the waste to be generated by the increase in population and tourists may not be a problem for other countries, but it is a big issue in a small island, like Guam, as it will affect its sustainability. Plus, creating a social value of one's home, neighbourhood, and community through influencing one to adopt a smart living (environmental friendlier life) and a smart environment (sustainable resource management and greener environment) can serve as a catalyst for cities achieving 'smart' sustainable growth (So and $\mathrm{Xu}, 2014$; 
The World Bank, 2014b). Given these arguments, how can 'smart' sustainable cities arise?

In recent years, there are a number of research studies conducted all over the world investigating what factors are affecting people's decision to adopt an environmental friendlier life through actively participating in household recycling and waste management. One example is the study conducted by Nishio and Takeuchi (2005) using Japanese subjects, which suggested that constructs such as media contact (MC), environmental involvement (EI), perceived cost (PC), perceived benefit (PB), subjective norms, etc., are affecting people's decision on adopting household recycling and waste management. In this study, we use the model developed by Nishio and Takeuchi (2005) as a reference and explore whether the cultural differences between Japan and Guam will have an impact on how the people from these two cultures adopt their environmental friendlier lifestyle. We hope that we can use the adoption of household recycling and waste management as the tools to probe into the issues on how to (re)develop Guam as a smart city. Plus, as far as we understand, this study is one of the early studies using the smart city angle to address the waste management issue in an island community (and in particular, in Western Pacific and Guam), which will enrich the literature in this area.

This paper is developed as follows. In Section 2, we will first provide the background of the study, including the literature on smarts cities and waste management, and the issues related to the waste management on Guam. Then, we will present the research model in Section 3. Afterwards, we will report our research methodology, data collection and data analysis in Section 4. In Section 5, we will discuss our findings and how we can apply the findings to (re)develop Guam to become a smart city/island. We will conclude our paper in Section 6 for providing our insights for future research in smart city.

\section{Literature review}

\subsection{Smart cities and waste management}

According to The World Bank (2014b), almost two thirds of the world's population will be living in cities by 2030. This requires the development of sustainable solutions for urban living. The efficient use and responsible handling of resources are important, while tackling municipal solid waste effectively is even more important. As more people move to cities, they are generating more trash. Trash piles create a public health problem, which make your city less attractive for economic development. As a result, these trends support the development of Smart City concepts, which are intended to improve living in urban areas by using innovative technologies (Pepperl and Fuchs, 2016).

In the USA, technologies are widely used in waste management (Smart Cities Council, 2016). For example, San Jose has launched an app that citizens can use to report illegal dumping. Dallas, meanwhile, has installed motion-activated cameras in strategic areas; most of its illegal dumping problem has been in more rural areas, On the other hand, Washington, DC, and Kirkland are using sensors to monitor waste levels in their receptacles.

In Europe, there are waste management systems developed with smart cities initiative with the aim of getting ahead of the social, economic, and environmental consequences (Smart Cities Council, 2016). Smart waste management systems are built with sensors installed in waste containers to detect the fill level inside, while measured data as well as 
sensor information are transmitted to the cloud and serve as a basis for optimised routes for waste collection (Pepperl and Fuchs, 2015). In a smart city project in Barcelona (Pepperl and Fuchs, 2016), a smart waste management system has been adopted. Garbage containers equipped with sensors transmit signals to indicate that they are full and should be emptied. Via the mobile communications network, the signals are sent to a web-based software application used by the waste management company for planning the best route for waste collection - garbage trucks travel only to those containers that actually need to be emptied. As a result, the overall efficiency and operational cost of the City's waste management has been greatly improved with cost savings of $35 \%$ and less waste overflow, hence more hygienic and less gas emissions (Pepperl and Fuchs, 2015, 2016).

Many of these smart system ideas would have been prohibitively expensive or even outright impossible in the past, but thanks to advances in technology - including inexpensive sensors, networks and predictive analytics - these ideas can be deployed quickly. Furthermore, the same principles that are driving these solutions can be applied to other smart cities challenges. However, there are factors such as culture and individual behaviour affecting the readiness of a place adopting smart cities initiative. Further research into pro-environmental behaviour deems necessary.

\subsection{Research in household recycling and waste management research}

Recycling and waste management are important elements for the smart and sustainable growth (So and Xu, 2014; World Bank, 2014b), and they can bring a greener society with lower carbon emission (So, 2013). To make people aware of the importance of these issues and take up positive steps towards adopting an environmental friendlier life which can lead to a smart and sustainable growth of the city, prior research has reported that the environmental condition is an important factor as it would have an impact on people's attitude and behaviour towards environmental policies (Gilbertson et al., 2011).

In order to get some insights on how to implement a successful household recycling program, some researchers conducted case studies to probe into some successful cases for studying the effectiveness of household recycling initiatives developed by municipal governments. For example, Losee et al. (2003) conducted a case study on the Efficient Brisbane Programme and studied its effectiveness on waste reduction.

Many environmental psychologists are also interested in the waste management problem. In particular, they are interested in factors affecting citizens' adoption of waste management. For example, Swami et al. (2011) studied how personality and individual difference affect household waste management behaviour. They noted that age, gender, Machiavellianism, conscientiousness and political cynicism are factors affecting household waste management behaviour. More recently, Mickaèl and Sébastien (2016) studied how displaying feedback and social comparative feedback affect the recycling practices in university environment, and showed that social comparative feedback has a more significant impact on recycling.

To find out the factors affecting the adoption of recycling and waste management behaviour by the general public, Lee and Paik (2011) studied conducted a survey in South Korea to investigate the food separation behaviour and recycling behaviour of people living in Seoul. They show that environmental attitudes, age and income level are having significant impact on the waste management behaviour adopted by South Koreans. Sidique et al. (2010) also reported that the adoption of recycling behaviour is affected by age, income, education, household size and convenience of the recycling 
locations. Nishio and Takeuchi (2005) also conducted a study using Japanese subjects, and we will use it as the foundation of this study, and we will describe its details in the next section of this paper.

\subsection{Waste management on Guam}

Guam is one of the states in the Pacific, which faces critical problems in various issues in waste management (Morrison and Munro, 1999). One of the major waste management issues faced by the Guamanian is the management of solid wastes. In the past 60 years, all the solid wastes of the island were disposed at a dumping site near the village of Ordot, which created a serious environmental problem as the leachate of the dumping site used to run over to the river nearby and polluted the nearby areas, as well as the ocean area nearly the outlet of the river, the Pago Bay (Denton et al., 2007) is dumping site is an important topic on Guam in various issues, ranged from environmental protection, solid waste management, and to the government budget. Due to the seriousness of the environmental problem concerned, the Federal Government of the US sued GovGuam for violation of the Federal Water Pollution Control Act, which is better known as the Clean Water Act in the US (US Senate Committee on Environment and Public Works, 2002). Eventually, the Court ordered the GovGuam should close the dumping site, and the site was formally closed on 31 August, 2011 (Guam Solid Waste Authority, 2011). At the time when we are preparing this article, the GovGuam hires a contractor to handle the capping of this dumping site.

To handle the municipal solid wastes generated by the local community after the closure of the dumping site in Ordot, 11-cell engineered landfills were built and are currently in operation. This landfill, i.e., the Dandan Landfill, is expected to have a lifespan of 30 years (Guam Solid Waste Authority, 2015). At the same time, the GovGuam started to promote the concept of reducing waste and recycling in the community, and the local university also participated in promoting the campus greening process (Santos, 2009).

To cope with the uncertainty in managing the resources (Rouse and Norton, 2010) on Guam to cater for sustainable development in the next five decades, the GovGuam has started to Imagine Guam Project to develop the blueprint for the future development of Guam. We hope that, through conducting this study, we can provide some insights to the GovGuam and the members of the public on how the Guamanian should move forward in their waste management planning so as to move Guam to become a smart city.

\section{Development of research model}

In this study, we would like to find out the Guamanian's perception on household recycling and waste management. We will investigate into this issue using the model developed by Nishio and Takeuchi (2005), and based on prior research (Ho, 2012), we understand that culture plays an important role in the formation of a behaviour and thus, we would include it as a key parameter in this research. In the subsequent sub-sections, we will first discuss the Hofstede Cultural dimension, which is the theoretical paradigm that we will use in this study, and then we will discuss the development of our research model. 


\subsection{Cultural dimensions}

Getting a new custom adopted, even when it has obvious advantages is often very difficult, as changes require a lengthy period, from the time it first appears to the time it is widely adopted, and people' $s$ behavioural intention of acceptance is the key to success (Taylor and Todd, 1995). Therefore, it is important to understand people's attitude and behaviour towards the acceptance of sustainable or green lifestyle. Prior research (Ho, 2012) has shown that the cultural background of people would have an impact on human behaviour. These research studies usually use the Hofstede cultural dimensions (Hofstede, 2001) as the basis for measuring the differences in culture. Table 1 provides the definition of the five dimensions of the Hofstede cultural dimensions and Table 2 reports the Hofstede cultural dimension scores for Guam and Japan.

Table 1 Hofstede cultural dimensions

\begin{tabular}{ll}
\hline Cultural dimension & Definition \\
\hline Power distance & $\begin{array}{l}\text { The extent to which the less powerful members of the institutions and } \\
\text { organisations with a country expect and accept that power is distributed } \\
\text { unequally [Hofstede, (2001), p.98]. }\end{array}$ \\
Individualism & $\begin{array}{l}\text { It refers to a society in which the ties between individual are loose } \\
\text { [Hofstede, (2001), p.225]. }\end{array}$ \\
Masculinity & $\begin{array}{l}\text { It refers to a society in which social gender roles are clearly distinct } \\
\text { [Hofstede, (2001), p.207]. }\end{array}$ \\
Uncertainty & $\begin{array}{l}\text { The extent to which the members of a culture feel avoidance threatened } \\
\text { by uncertainty or unknown situation [Hofstede, (2001), p.161]. }\end{array}$ \\
Long-term & $\begin{array}{l}\text { It stands for the fostering of virtues oriented orientation towards future } \\
\text { rewards, in particular, perseverance and thrift [Hofstede, (2001), p.359]. }\end{array}$ \\
\hline
\end{tabular}

As shown in Table 2, Guam and Japan are having a totally different culture. Thus, we can expect that people from Guam and Japan probably have a different way to formulate their adoption behaviour in relation to the household recycling and waste management behaviour.

Table 2 Hofstede cultural dimensions score of Guam and Japan

\begin{tabular}{lccccc}
\hline Country & $\begin{array}{c}\text { Power } \\
\text { distance }\end{array}$ & Individualism & Masculinity & $\begin{array}{c}\text { Uncertainty } \\
\text { avoidance }\end{array}$ & $\begin{array}{c}\text { Long-term } \\
\text { orientation }\end{array}$ \\
\hline Guam & 11 & 86.5 & 25.9 & 55.4 & 39.8 \\
Japan & 54 & 46 & 95 & 92 & 88 \\
\hline
\end{tabular}

Source: Scores for Japan are obtained from http://geert-hofstede.com on

03.08.2016. Scores for Guam are obtained from Perez et al. (2015)

\subsection{Research model}

Figure 1 provides the major findings reported by Nishio and Takeuchi (2005). The details of the constructs used in the model are listed in Table 3. It is noted that all paths shown in Figure 1 are having positive impacts, except EI is having a negative impact on PC, and PC has a negative impact on the attitude towards waste reduction (ATT). 
Figure 1 Research model proposed by Nishio and Takeuchi (2005) (a.k.a. model 1)

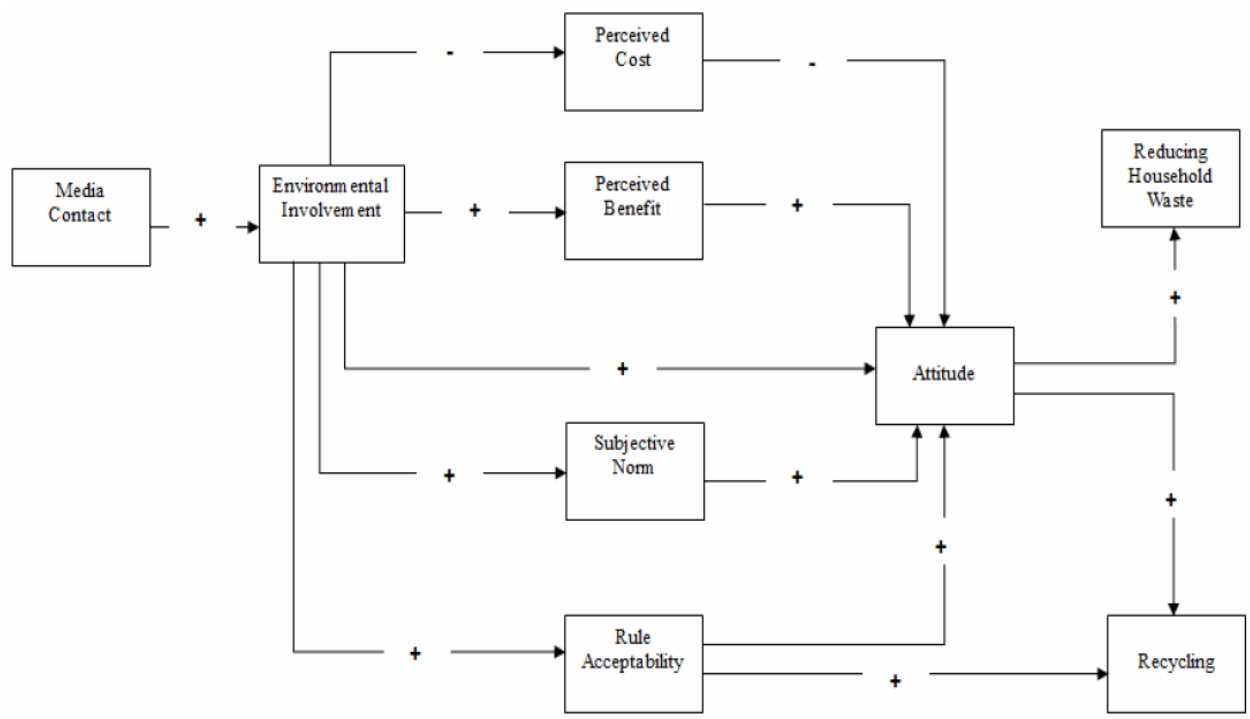

We have developed a two-step process for developing and testing our research model: First, we collect data and conduct an analysis using the Nishio and Takeuchi (2005) (a.k.a. model 1) to investigate whether the cultural differences between Guam and Japan will have an impact on how the people adopt their environmental friendlier lifestyle. Second, we further explore if we can develop an alternative model (a.k.a. model 2) based on the result found on the model 1, which can better predict how Guamanian develop their environmental friendlier lifestyle.

Table 3 Definition of constructs used in Nishio and Takeuchi (2005)

\begin{tabular}{ll}
\hline Construct & Details \\
\hline Media contact (MC) & $\begin{array}{l}\text { It is a 5-item measurement developed by Nishio (2002) of the level } \\
\text { of the media contact of environmental issues received by a user. } \\
\text { This helps us to measure the frequency of our subjects received } \\
\text { environmental information through the media (such as TV and } \\
\text { printed materials). }\end{array}$ \\
It is a 4-item measurement developed based on Aoki et al. (1988) \\
on a user's involvement in making an environmental friendlier \\
life. This helps us to measure whether our subjects' involvement in \\
involvement (EI) & $\begin{array}{l}\text { implementing waste management and recycling practices in their } \\
\text { own household. }\end{array}$ \\
& $\begin{array}{l}\text { It is a 3-item measurement developed by Nishio and Takeuchi } \\
\text { (2005) on a user's perception of the cost involved in having an }\end{array}$ \\
environmental friendlier life, including both the tangible cost (such \\
as money) and intangible cost (such as time) involved in practicing \\
an environmental friendlier lifestyle. \\
It is a 2-item measurement developed by Nishio and Takeuchi \\
(2005) on a user's perception of the benefit gained in having an \\
environmental friendlier life, including both tangible and \\
intangible savings.
\end{tabular}


Table 3 Definition of constructs used in Nishio and Takeuchi (2005) (continued)

\begin{tabular}{|c|c|}
\hline Construct & Details \\
\hline Rule acceptability (RA) & $\begin{array}{l}\text { It is a } 3 \text {-item measurement developed by Nishio (2002) on the } \\
\text { degree of a user's discretion on involving in recycling and waste } \\
\text { reduction activities. In particular, we measure our subjects' } \\
\text { acceptance in following the rules and norms related to recycling } \\
\text { and waste reduction activities. }\end{array}$ \\
\hline Subjective norm (SN) & $\begin{array}{l}\text { It is a 3-item measurement developed based on Taylor and Todd } \\
\text { (1995) for measuring the influence of the norm of family, friends } \\
\text { and neighbourhood on a user's decision on the involvement in } \\
\text { environmental friendlier life. }\end{array}$ \\
\hline $\begin{array}{l}\text { Attitude towards waste } \\
\text { reduction (ATT) }\end{array}$ & $\begin{array}{l}\text { It is a 3-item measurement developed by Nishio and Takeuchi } \\
\text { (2005) for measuring the overall attitude of a user toward the } \\
\text { environmental problems and behaviour. In particular, we measure } \\
\text { our subjects' attitude on adopting waste reduction activities. }\end{array}$ \\
\hline Recycling (R) & $\begin{array}{l}\text { It is a 5-item measurement developed by Nishio and Takeuchi } \\
(2005) \text { for measuring the level of participation in recycling } \\
\text { behaviour of a user. This includes measuring whether our subjects } \\
\text { would like to repair broken items for recycling, and to use } \\
\text { products that can be recycled. }\end{array}$ \\
\hline $\begin{array}{l}\text { Reducing household } \\
\text { waste (RHW) }\end{array}$ & $\begin{array}{l}\text { It is a 6-item measurement developed by Nishio and Takeuchi } \\
\text { (2005) for measuring the level of reduction of household waste of } \\
\text { a user. We measure whether our subjects would like to consider } \\
\text { the household waste to be generated in supporting their lifestyle. }\end{array}$ \\
\hline
\end{tabular}

\section{Methodology and data analysis}

To test whether model 1 can predict how Guamanian develop our environmental friendlier lifestyle, we conducted a survey based on the questionnaire used by Nishio and Takeuchi (2005) (see Appendix A) using student subjects enlisted from management information systems courses at a public university on Guam. The survey used a seven-point Likert scale. In this study, we recruited Guam college students to participate in the survey as they are the future stakeholders of the society. To encourage our subjects to participate in this survey, an extra credit of $2 \%$ of the course grade was given as an incentive. Ninety students participated in this survey, of which 33 (or 36.7\%) of them were male. The gender ratio is close to the one of the university population. The average age was 22.8 .

In this study, we used SmartPLS Version 2.0 M3 (Ringle et al., 2005) to analyse our structural model, with bootstrapping algorithm with 100 cases and 2,500 re-sampling for calculating the $t$-values of the factor loadings and path coefficients. After the factor analysis, we noted that four items, i.e., R1, R3, RHW1 and RHW2 are having low loadings towards their respective constructs, and thus, are removed from our model. The factor loadings, Cronbach's alpha, and composite reliability of the model 1 are reported in Appendix B, and the correlation matrix is reported in Appendix C.

The results found using the model 1 is reported in Figure 2. We observe the following: 
1 EI does not have an impact to PC, and PC does not have any impact on ATT

2 while EI has an impact on PB, PB does not have any impact on ATT

3 while EI has an impact on RA, RA does not have any impact on ATT and RHW.

In other words, the model 1 is unable to predict the roles of PB, PC and RA in the formulation of environmentally friendly behaviours (i.e., recycling and reducing of household waste). Plus, the model cannot explain how PC is formed.

Figure 2 PLS result of the model proposed by Nishio and Takeuchi (2005)

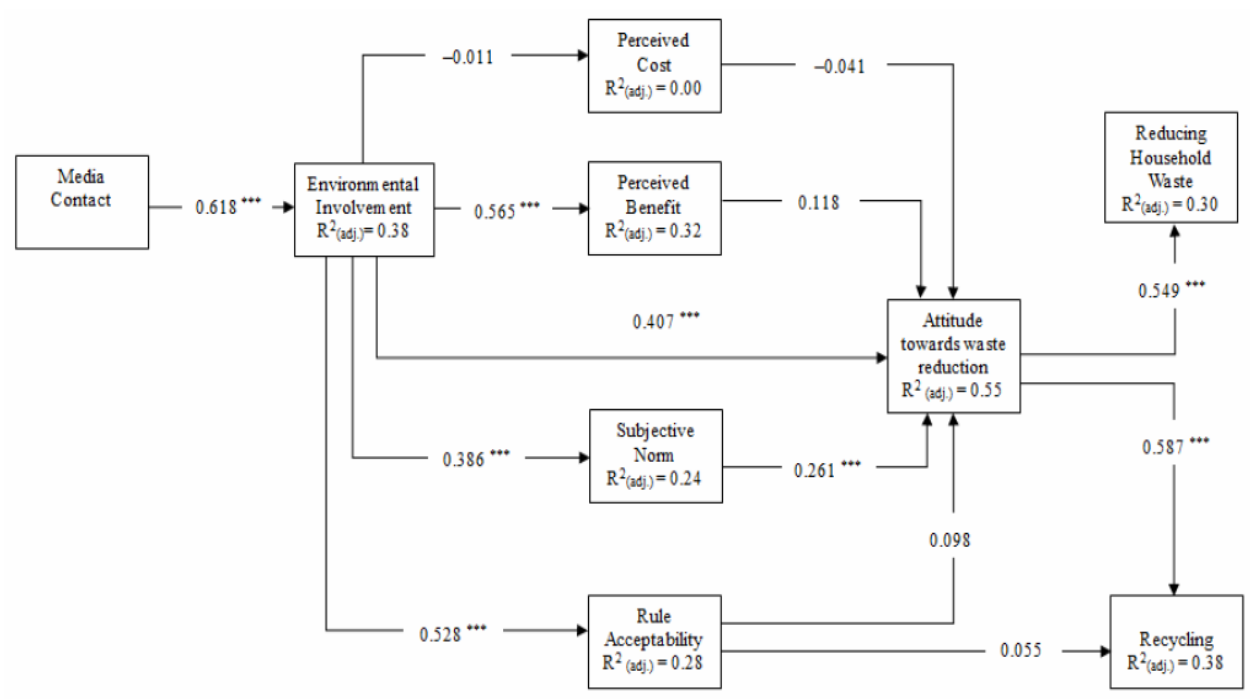

Note: ${ }^{* *} p<0.01 ; * * p<0.05 ; * p<0.1$

Based on the finding of the Model 1, we develop the model 2 by including/excluding the following paths in the model. If the model 2 is a better model, we will be able to find more significant relationships (i.e., paths) and the $R^{2}$ (adj.) values will increase for the dependent variables:

1 As shown in the model 1, EI does not have a direct impact on PC. Thus, one of the possible factors which will have an impact to PC would be MC. It is because the information provided in the media will be handy sources for people to form their opinion. Then, we propose to test whether the level of information related to environmentally friendly life presented in the media will help to reduce (i.e., having a negative correlation) people's idea of the $\mathrm{PC}$ in relation to live an environmental friendlier life. Also, we remove the impact of EI on PC (in the model 1) in the model 2.

2 For PC, it is possible that it will have direct impacts on R and RHW, instead of mediated by ATT. Therefore, we propose to test these two relationships (i.e., whether PC has impacts on R and RHW, respectively). Also, we remove the proposed impact of PC on ATT (in the model 1) in the model 2. 
3 Similar to PC, we also propose that it is possible for PB to have direct impacts on R and RHW, respectively. Therefore, we propose to test these two relationships (i.e., whether PB has impacts on R and RHW, respectively). We also remove the proposed impact of PB on ATT (in the model 1) in the model 2.

4 From the model 1, we note that RA does not have any impact on ATT and R. After further reviewing the items proposed by Nishio and Takeuchi (2005), we would suggest that these items are more related to the PC and benefit issues of living an environmental friendlier life. Therefore, we propose to test these relationships (i.e., whether RA has impacts on $\mathrm{PB}$ and $\mathrm{PC}$, respectively). We also remove the proposed impacts of RA to ATT and R (in the model 1) in the model 2.

5 After further reviewing the survey items, we would suggest that $\mathrm{SN}$ will have an impact on RA. It is because the items of RA are rules and norms developed by the community and thus, it is likely that if the level of SN increases, the level of RA will also increase. Therefore, we propose to test whether $\mathrm{SN}$ will have a positive impact on RA in model 2.

The results found using the model 2 is reported in Figure 3, and the factor loadings, Cronbach's alpha, and composite reliability of model 2 are reported in Appendix D, and the correlation matrix is reported in Appendix E.

Figure 3 PLS result of the alternative model (a.k.a. the model 2)

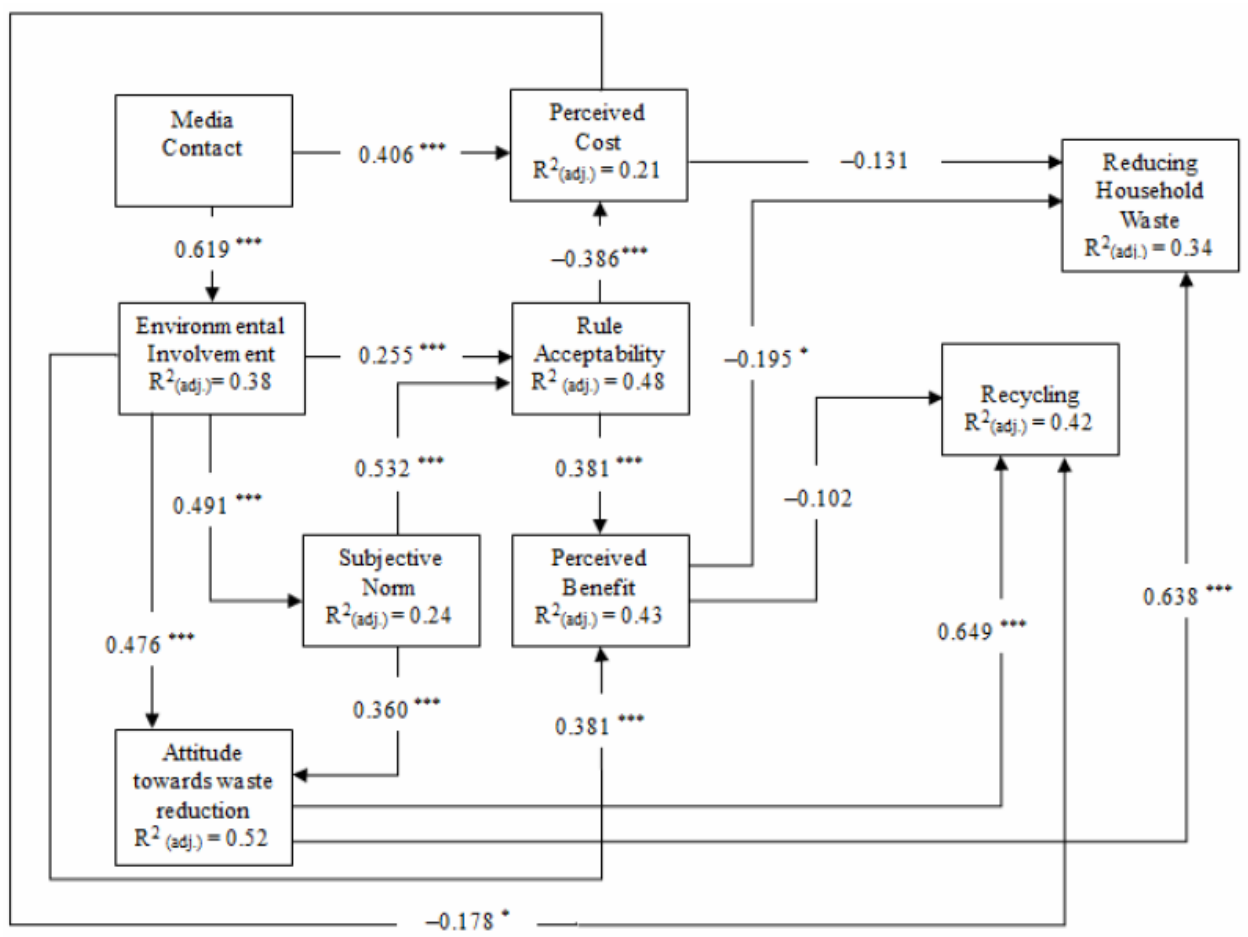

Note: ${ }^{* * *} p<0.01 ; * * p<0.05 ;{ }^{*} p<0.1$ 
Table 4 provides the comparison between the model 1 and the model 2 . It is observed that:

1 generally speaking, the model 2 has more paths with significant results (and the results will be discussed in the next section)

2 most of the $\mathrm{R}^{2}$ (adj.) values are increased.

In brief, we can say that the model 2 provides a better explanation of the relationships in the model than the model 1. It also supports our prediction that Guamanian and Japanese have a different way to formulate their environmental friendlier lifestyle.

\section{Discussion}

The result of this study shows that Guamanian and Japanese have a different ways to formulate the environmental friendlier lifestyle. First, while in both cases that MC has an impact on people from these two cultures to formulate their ideas on whether they will involve in an environmental friendlier life, the MC plays an important role in passing the message about PC an environmental friendlier life on Guam $(\beta=0.406$, with $\mathrm{p}<0.01)$. Unfortunately, the impact of $\mathrm{MC}$ is positive to the $\mathrm{PC}$, i.e., the higher the level of $\mathrm{MC}$ that the young people on Guam received on environmental friendlier life, the higher the level that they believe that it is costly to practice an environmental friendlier life (!!!). Therefore, when we would like to disseminate the information to the public, we should try to put more efforts to deliver the benefits bring by the environmental friendlier life to the public.

Second, we note that subjective norm (SN) has a significant positive impact on the rule acceptability (RA) as we predicted $(\beta=0.532$, with $p<0.01)$ on Guam only. As suggested, it is because when our friends and relatives have a positive attitude towards an environmental friendlier life, it will help us to be more aware of the 'custom' of practicing such as lifestyle. This also shows the importance for us to conduct the publicity in the society to promote the environmentally friendlier life as it will help us to strengthen people's ideas of 'environmentally friendly custom' in the society.

Third, we noted the RA has significant impacts on PB and PC on Guam. It is positively affecting the beliefs in $\mathrm{PB}(\beta=0.381$, with $\mathrm{p}<0.01)$, and negatively affecting the beliefs in PC $(\beta=-0.386$, with $p<0.01)$. That means if we can effectively enhance the level of the ideas of accepting the 'environmentally friendly custom' on Guam, it will benefit the society by enhancing people's beliefs in the benefit, and reducing people's belief in the cost, of living an environmentally friendly way.

The last but not least, we also discovered two marginal effects (i.e., p < 0.1) on Guam. While the level of PC does not have any impact on our ATT on Guam, it has a marginal negative impact on the level of recycling $(\beta=-0.178$, with $p<0.10)$. This result means that if the people believe that it is costly (in terms of time used in participating in recycling, for example) to engage in an environmental friendlier life, they are more likely to reduce their level of participation. With this result, we should find ways to reduce people's belief in the impact of PC in practicing an environmental friendlier life, which can be done by using a better designed media campaign (i.e., to reduce the level of impact of $\mathrm{MC}$ ) and reinforcing the environmentally friendly 
custom on Guam as mentioned above. A community-based recycling project would be a possible starting point for tackling this issue (Singhirunnusorn et al., 2012).

Table 4 Results of model 1 and model 2

\begin{tabular}{|c|c|c|c|c|}
\hline \multirow{2}{*}{ Path } & \multicolumn{2}{|c|}{ Model 1} & \multicolumn{2}{|c|}{ Model 2} \\
\hline & Path coeff. & $R^{2}$ (adj.) & Path coeff. & $R^{2}$ (adj.) \\
\hline \multicolumn{5}{|c|}{ Environmental involvement (EI) } \\
\hline $\mathrm{MC} \rightarrow \mathrm{EI}$ & $0.619 * * *$ & 0.38 & $0.618 * * *$ & 0.38 \\
\hline \multicolumn{5}{|c|}{ Perceived benefit (PB) } \\
\hline $\mathrm{EI} \rightarrow \mathrm{PB}$ & $0.565 * * *$ & 0.32 & $0.368 * * *$ & 0.43 \\
\hline $\mathrm{RA} \rightarrow \mathrm{PB}$ & - & & $0.381 * * *$ & \\
\hline \multicolumn{5}{|c|}{ Perceived cost (PC) } \\
\hline $\mathrm{EI} \rightarrow \mathrm{PC}$ & -0.011 & 0.00 & - & 0.21 \\
\hline $\mathrm{MC} \rightarrow \mathrm{PC}$ & - & & $0.406^{* * *}$ & \\
\hline $\mathrm{RA} \rightarrow \mathrm{PC}$ & - & & $-0.386^{* * *}$ & \\
\hline \multicolumn{5}{|c|}{ Rule acceptability $(R A)$} \\
\hline $\mathrm{EI} \rightarrow \mathrm{RA}$ & $0.528 * * *$ & 0.28 & $0.255 * * *$ & 048 \\
\hline $\mathrm{SN} \rightarrow \mathrm{RA}$ & - & & $0.532 * * *$ & \\
\hline \multicolumn{5}{|c|}{ Subjective norm (SN) } \\
\hline $\mathrm{EI} \rightarrow \mathrm{SN}$ & $0.491 * * *$ & 0.24 & $0.491 * * *$ & 0.24 \\
\hline \multicolumn{5}{|c|}{ Attitude towards waste reduction (ATT) } \\
\hline $\mathrm{EI} \rightarrow \mathrm{ATT}$ & $0.407 * * *$ & 0.55 & $0.476 * * *$ & 0.52 \\
\hline $\mathrm{PB} \rightarrow \mathrm{ATT}$ & 0.118 & & & \\
\hline $\mathrm{PC} \rightarrow \mathrm{ATT}$ & -0.041 & & & \\
\hline $\mathrm{RA} \rightarrow \mathrm{ATT}$ & 0.098 & & & \\
\hline $\mathrm{SN} \rightarrow \mathrm{ATT}$ & $0.261 * * *$ & & $0.360 * * *$ & \\
\hline \multicolumn{5}{|c|}{ Recycling $(R)$} \\
\hline $\mathrm{ATT} \rightarrow \mathrm{R}$ & $0.587 * * *$ & 0.38 & $0.649 * * *$ & 0.42 \\
\hline $\mathrm{RA} \rightarrow \mathrm{R}$ & 0.055 & & & \\
\hline $\mathrm{PB} \rightarrow \mathrm{R}$ & - & & -0.102 & \\
\hline $\mathrm{PC} \rightarrow \mathrm{R}$ & - & & $-0.178^{*}$ & \\
\hline \multicolumn{5}{|c|}{ Reducing household waste (RHW) } \\
\hline $\mathrm{ATT} \rightarrow \mathrm{RHW}$ & $0.549 * * *$ & 0.30 & $0.638 * * *$ & 0.34 \\
\hline $\mathrm{PB} \rightarrow \mathrm{RHW}$ & - & & $-0.195 *$ & \\
\hline $\mathrm{PC} \rightarrow \mathrm{RHW}$ & - & & -0.131 & \\
\hline
\end{tabular}

Note: ${ }^{* *} p<0.01 ; * * p<0.05 ; * p<0.1$

The second marginal effect that we observed is counterintuitive. While the level of PB does not have any impact on our ATT on Guam, it has a marginal negative impact on the level of reducing household waste (RHW) $(\beta=-0.195$, with $p<0.10)$. In other words, it means that while people believe that environmental friendlier life can help them to live a more quality lifestyle and reduce their household budget, they think that such benefit can bring sufficient benefit to them so that they can be less concern on reducing their 
household waste (by using reusable containers). One of the possible reasons for having this counterintuitive result is possible that the people living on Guam have established a lifestyle for not using reusable containers for years and thus, while we agree that that there are $\mathrm{PB}$ in practicing an environmental friendlier lifestyle, we are unable to link up the fact that the use of reusable containers can bring benefit to us. Instead, we are of the view that as there are other benefits bring by an environmental friendlier lifestyle, we can have a better reason to reduce the use of reusable containers.

\section{Conclusions, limitations and future research directions}

To conclude, this study, through studying and understanding the waste management problem faced by Guam which is on one hand a unique scenario faced (as there should not be many cases for a small community be involved in a major military redeployment), and on the other hand, many small nations in the Pacific Ocean are sharing the geographic and environmental problem of Guam, i.e., a small island with a small population which would like to expand their tourist industry and have sustainability and waste management as a major issues to be handled. This study provides some insight for policy makers to find ways to better understand their own problems. In sum, this study provides us with some initial thoughts in promoting the environmental friendlier lifestyle on Guam with the aim of building Guam a 'smart' sustainable city through:

1 designing a better media campaign, which focuses on promoting the benefit for living an environmental friendlier life, and provide clarification (for reducing) the cost related to it

2 investing more in the development of SNs of living an environmental friendlier life, which can strengthen the level of RA (for following an environmental friendlier custom in the society) on Guam.

This can improve people's understanding of the PB and PC concerned. Plus, we should try to be aware of the possibility of some existing lifestyle of the local community would reduce the impacts of our campaign (such as people cannot align the PB of living an environmental friendlier life with their need to reduce their household waste). The last but not least, our result also shows that Japanese (model 1) and Guamanian (model 2) are having two different conceptual models in developing their environmental friendliness lifestyle. In other words, we found empirical evidence to show that development of environmental friendliness lifestyle is culture-dependent. However, based on the current analysis, we cannot directly compare and conclude which culture has a better lifestyle in terms of environmental friendliness as the focus of this study is to find out how different constructs are affecting the formation of the lifestyle.

This study also has a few limitations. First, we have recruited 90 subjects to participate in this survey, which is relatively small compared with other studies. However, our sample size is already more than the minimum sample size required for conducting PLS. According to Gefen et al. (2000), minimum sample size for conducting PLS is 'at least 10 times the number of items in the most complex construct'. As our most complex construct, i.e., MC, has 5 items, the minimum sample size is 50 . Therefore, we are of the view that our sample size is sufficient to conduct analyses and make wide conclusions. 
Regarding future studies, there is room for studies considering other factors that might influence the relationship between pro-environmental behaviour and sustainability adoption. A smart city finds ways to use technology to make life easier for their residents and visitors. Authorities invest not only in human and social capital, but also traditional (e.g., transport) and modern (e.g., digital) communication infrastructure to fuel sustainable economic growth and a high quality of life, with effective sustainability systems and services (e.g., waste management system) using innovative technologies [e.g., smart grids and internet of things (IoT)] (The World Bank, 2014b). One potential area for future research is to investigate the interaction of social and individual factors that creates the conditions for influencing pro-environmental behaviour leading to better environmental performance. For example, one as a member of social networks may adopt a new custom not entirely because of its individual usefulness but because of perceived social pressure. Such pressure may be perceived as coming from individuals whose beliefs and opinions are important, including peers and people who are in social networks. This is something that future studies should consider as it might provide insight into the relationship between pro-environmental behaviour and sustainability adoption. City management is suggested to adopt a coherent strategy for harnessing smart technology in a way that improves quality of life for residents and visitors where various social, cultural, geo-political and technological factors are involved and these factors will be converging to drive a tremendous amount of innovation in this space.

\section{References}

Aoki, Y., Saito, M., Sugimoto, T. and Moriguchi T. (1988) 'Conceptualizing and measuring the consumer involvement construct', Proceedings of Japan Society of Marketing and Distribution, pp.157-162.

Denton, G.R.W., Olsen, M.C. and Wen, Y (2007) 'Solid waste disposal on Guam: the impact of an unsanitary landfill on the heavy metal status adjacent aquatic community representatives', Progress in Environmental Science and Technology, Vol. 1, pp.1169-1176 (accessed 1 December 2015).

Gefen, D., Straub, D. and Boudreau, M-C. (2000) 'Structural equation modeling and regression: guidelines for research practice', Communications of the Association for Information Systems Vol. 4, Article 7 (accessed 1 December 2015).

Gilbertson, M., Hurlimann, A. and Dolnicar, S. (2011) 'Does water content influence behaviour and attitudes to water conservation?', Australasian Journal of Environmental Management, Vol. 18, No. 1, pp.47-60.

Guam Solid Waste Authority (2011) Ceremonies for closing of Ordot Dump and Opening of the Layon Landfill, Guam Solid Waste Authority [online] http://www.guamsolidwasteauthority.com/pr_11_08_18.html (accessed 1 December 2015).

Guam Solid Waste Authority (2015) Layon Landfill, Guam Solid Waste Authority [online] http://www.guamsolidwasteauthority.com/gswa-layon-landfill.shtml (accessed 1 December 2015).

Guam Visitors Bureau (2014) Guam Tourism 2020 [online] https://www.guamvisitorsbureau.com/ docs/research-and-reports/reports/guam-tourism-2020-plan/guam-tourism-2020-plan.pdf.

Helmer, O. (1967) Analysis of the Future: The Delphi Method, RAND Corporation.

Ho, K.K.W. (2012) 'A study on the intention to adopt third generation (3G) wireless service on a small community with unique culture: the use of Hofstede cultural dimensions in predicting the interaction between culture and the technology acceptance model on Guam', International Journal of Systems and Service-Oriented Engineering, Vol. 3, No. 4, pp.57-77. 
Hofstede, G.H. (2001) Culture's Consequences: Comparing Values, Behaviors, Institutes, and Organizations across Nations, 2nd ed., Sage Publications, Inc.

Imagine Guam (2016) [online] http://www.imagine.guam.gov.

Lee, S. and Paik, H.S. (2011) 'Korean household waste management and recycling behaviour', Building and Environment, Vol. 46, No. 5, pp.1159-1166.

Losee, S., Cornes, V., Wyatt, D. and Downs, B. (2003) 'Promoting energy and resources efficiency households: Brisbane City Council's Efficient Brisbane Program', Australasian Journal of Environmental Management, Vol. 10, No. 2, pp.85-95.

Mickaèl, D. and Sébastien, M. (2016) 'Increasing recycling through displaying feedback and social comparative feedback', Journal of Environmental Psychology, Vol. 48, pp.101-107.

Morrison, R.J. and Munro, A.J. (1999) 'Waste management in the small island developing states of the South Pacific: an overview', Australian Journal of Environmental Management, Vol. 6, No. 4, pp.232-246.

Nishio, C. (2002) 'Factors affecting the ecological behavior of Japanese individuals', Japan Marketing Journal, Vol. 21, No. 3, pp.4-15.

Nishio, C. and Takeuchi, T. (2005) 'Factors of household recycling and waste reduction behavior', in Ha, Y-U. and Yi, Y. (Eds.): AP - Asia Pacific Advances in Consumer Research, Vol. 6, pp.46-51, Association for Consumer Research, Duluth, MN.

Owen, A. (2010) 'Guam culture, immigration and the US military build-up', Asia Pacific Viewpoint, Vol. 25, No. 3, pp.304-318.

Pepperl and Fuchs (2015) Smart Waste Management Solution with Sensor Technology, Pepperl+Fuchs GmbH [online] https://www.youtube.com/watch?v=fFPJfqp6Qx0 (accessed 1 December 2015).

Pepperl and Fuchs (2016) Smart Waste Management with Sensorik4.0®, Pepperl+Fuchs GmbH [online] http://www.pepperl-fuchs.com/global/en/27019.htm (accessed 1 December 2015).

Perez, K., Dote, K., Damian, J., Taylor, M. and Dickens, A. (2015) 'Guam and Saipan's business culture: Deriving Hofstede's score', Pacific Center for Economic Initiatives [online] http://www.uogonline.com/pcei/documents/Perez,\%20K.,\%20et\%20al.pdf (accessed 1 December 2015).

Ringle, C.M., Wende, S. and Will, A. (2005) 'SmartPLS 2.0 (beta)' [online] http://www.smartpls.de (accessed 1 December 2015).

Rouse, H.L. and Norton, N. (2010) 'Managing scientific uncertainty for resource management planning in New Zealand', Australasian Journal of Environmental Management, Vol. 17, No. 2, pp.66-76.

Ruane, M.C.M. (2015) First Hawaiian Bank Economic Forecast - Guam-CNMI Edition 2015 [online] http://www.guamchamber.com.gu/docs/members/member-news/fourth-straight-yearof-stable-growth-in-2015.pdf (accessed 1 December 2015).

Santos, A.T. (2009) 'Going green: the impact on higher education institutions', Journal of International Business Research, Vol. 8, No. 2, pp.95-100.

Sidique, S.F., Lupi, F. and Joshi, S.V. (2010) 'The effects of behaviors and attitudes on drop-off recycling activities', Resources, Conservation and Recycling, Vol. 54, No. 3, pp.163-170.

Singhirunnusorn, W., Donlakorn, K. and Kaewhanin, W. (2012) 'Household recycling behaviours and attitudes waste bank project: Mahasarakham Municipality', Journal of Asian Behavioural Studies, Vol. 2, No. 6, pp.35-47.

Smart Cities Council (2016) 6 Cities That Are Fighting Trash with Technology, Smart Cities Council [online] http://smartcitiescouncil.com/article/6-cities-are-fighting-trash-technologyand-winning (accessed 15 February 2016).

So, S. (2013) 'An empirical model of sustainable manufacturing supply chains for enabling a low-carbon economy', International Journal of Electronic Business, Vol. 10, No. 3, pp.292-314. 
So, S. and $\mathrm{Xu}, \mathrm{H}$. (2014) 'A conceptual framework for adopting sustainability in greening the supply chains', International Journal of Logistics Systems and Management, Vol. 19, No. 4, pp.491-510.

Swami, V., Chamorro-Premuzic, T., Snelgar, R. and Furnham, A. (2011) 'Personality, individual differences, and demographic antecedents of self-reported household waste management behaviours', Journal of Environmental Psychology, Vol. 31, No. 1, pp.21-26.

Taylor, S. and Todd P. (1995) 'An integrated model of waste management behavior: a test of household recycling and composting intentions', Environment and Behaviour, Vol. 27, No. 5, pp.603-630.

The World Bank (2014a) Country Data - Guam [online] http://data.worldbank.org/country/guam (accessed 1 December 2015).

The World Bank (2014b) Sustainable and Smart Cities, Sustainable Development Network, The World Bank.

US Senate Committee on Environmental and Public Works (2002) Federal Water Pollution Control Act, As amended through P.L. 107-303, 27 November 2002 [online] http://www.epw.senate.gov/water.pdf (accessed 1 December 2015).

\section{Appendix A}

\section{Survey instruments}

\section{Media contact}

$\mathrm{MC1}$ I usually watch TV programs and read newspaper articles about environmental problems.

MC2 I usually read books about environmental problems.

MC3 I usually read advertisements and pamphlets from the government, and know our environmental policy and strategy.

MC4 I usually visit the environment related corner at industrial exhibitions.

MC5 I usually read environmental related articles and pamphlets of corporations, and know their environmental policy and strategy.

\section{Environmental involvement}

EI1 I try various innovations in leading an environmental friendlier life.

EI2 When I buy products, I usually think about the effect those products will have on the environment.

EI3 I have a special interest in waste problem within all the various environmental problems.

EI4 I think I have an in-depth knowledge on recycling.

\section{Perceived cost}

PC1 I feel that reducing waste and recycling is time consuming.

PC2 I believe that waste management and recycling is ineffective in relation to the efforts and cost incurred. 
PC3 I think that waste reduction and recycling is difficult while maintaining a convenient and comfortable lifestyle.

\section{Perceived benefit}

PB1 I believe that the effort to reduce waste reduces wastefulness, and leads to a quality lifestyle.

PB2 I believe that the effort to reduce waste is related to controlling household budget expenses, and is rational behaviour.

\section{Rule acceptability}

RA1 Since waste reduction and recycling can be done at ones own pace, it is easy.

RA2 It is easy to understand the city's waste separation and recycling rules.

RA3 Waste reduction and recycling has become a custom.

\section{Subjective norm}

SN1 My family has a positive attitude to waste reduction and recycling.

SN2 My friends and acquaintances have a positive attitude to waste reduction and recycling.

SN3 My living area has a positive attitude to waste reduction and recycling.

\section{Attitude towards waste reduction (ATT)}

ATT1 I like recycling and waste reduction.

ATT2 I intend to participate in area recycle and environmental cleanup activities.

ATT3 I communicate the importance of and recommend cooperation with recycling and waste reduction to those around me.

\section{Recycling $(R)$}

R1 I do not use the disposable products such as paper cup and chopsticks. (Item dropped).

R2 I thoroughly separate waste to make recycling easy.

R3 I consider empty bottle and cans not as waste but as recyclable products. (Item dropped).

R4 I take rinsed PET bottles and disposable plastic tray to the appointed waste collection area.

R5 I use broken products for a long time by repairing them. (Item dropped).

\section{Reducing household waste}

RHW1 I take a shopping bag when I go shopping. (Item dropped) 
RHW2 I make a shopping list so that I will not buy unnecessary products. (Item dropped)

RHW3 I choose products that come in a reusable container.

RHW4 I choose perishable foods not contained in disposable plastic tray.

RHW5 I choose products that come in reusable containers (e.g., bottled milk, soft drinks, etc.)

RHW6 I choose recycled products such as toilet paper made from waste paper. (Item dropped).

\section{Appendix B}

Factor loading of model 1

\begin{tabular}{|c|c|c|c|c|c|c|c|c|c|c|c|}
\hline & $A T T$ & $E I$ & $M C$ & $P B$ & $P C$ & $R$ & $R A$ & $R H W$ & $S N$ & $C A$ & $C R$ \\
\hline ATT1 & 0.86 & & & & & & & & & 0.84 & 0.90 \\
\hline AAT2 & 0.86 & & & & & & & & & & \\
\hline AAT3 & 0.88 & & & & & & & & & & \\
\hline EI1 & & 0.83 & & & & & & & & 0.86 & 0.91 \\
\hline EA2 & & 0.85 & & & & & & & & & \\
\hline EI3 & & 0.87 & & & & & & & & & \\
\hline EI4 & & 0.80 & & & & & & & & & \\
\hline MC1 & & & 0.73 & & & & & & & 0.85 & 0.89 \\
\hline $\mathrm{MC} 2$ & & & 0.82 & & & & & & & & \\
\hline MC3 & & & 0.82 & & & & & & & & \\
\hline MC4 & & & 0.78 & & & & & & & & \\
\hline MC5 & & & 0.81 & & & & & & & & \\
\hline PB1 & & & & 0.90 & & & & & & 0.73 & 0.88 \\
\hline PB2 & & & & 0.87 & & & & & & & \\
\hline PC1 & & & & & 0.76 & & & & & 0.68 & 0.82 \\
\hline PC2 & & & & & 0.86 & & & & & & \\
\hline PC3 & & & & & 0.69 & & & & & & \\
\hline $\mathrm{R} 2$ & & & & & & 0.90 & & & & 0.71 & 0.87 \\
\hline R4 & & & & & & 0.87 & & & & & \\
\hline RA1 & & & & & & & 0.79 & & & 0.76 & 0.86 \\
\hline RA2 & & & & & & & 0.77 & & & & \\
\hline RA3 & & & & & & & 0.88 & & & & \\
\hline RHW3 & & & & & & & & 0.89 & & 0.84 & 0.90 \\
\hline RHW4 & & & & & & & & 0.87 & & & \\
\hline RHW5 & & & & & & & & 0.82 & & & \\
\hline RHW6 & & & & & & & & 0.72 & & & \\
\hline SN1 & & & & & & & & & 0.86 & 0.80 & 0.88 \\
\hline SN2 & & & & & & & & & 0.86 & & \\
\hline SN3 & & & & & & & & & 0.82 & & \\
\hline
\end{tabular}

Notes: ATT: attitude towards waste reduction; EI: environmental involvement; MC: media contact; PB: perceived benefit; PC: perceived cost; R: recycling; RA: rule acceptability; RHW: reducing household waste; $\mathrm{SN}$ : subjective norm; CA: Cronbach's alpha; CR: composite reliability. 


\section{Appendix C}

Latent variable correlations of model 1

\begin{tabular}{lccccccccc}
\hline & $A T T$ & $E I$ & $M C$ & $P B$ & $P C$ & $R$ & $R A$ & $R H W$ & $S N$ \\
\hline ATT & 0.87 & & & & & & & & \\
EI & 0.65 & 0.84 & & & & & & & \\
MC & 0.45 & 0.62 & 0.79 & & & & & & \\
PB & 0.55 & 0.56 & 0.35 & 0.89 & & & & & \\
PC & -0.15 & -0.01 & 0.27 & -0.25 & 0.78 & & & & \\
R & 0.62 & 0.37 & 0.25 & 0.29 & -0.20 & 0.88 & & & \\
RA & 0.56 & 0.53 & 0.35 & 0.57 & -0.19 & 0.38 & 0.82 & & \\
RHW & 0.55 & 0.38 & 0.41 & 0.18 & -0.14 & 0.49 & 0.36 & 0.83 & \\
SN & 0.59 & 0.49 & 0.27 & 0.51 & -0.22 & 0.44 & 0.67 & 0.33 & 0.85 \\
\hline
\end{tabular}

Notes: ATT: attitude towards waste reduction; EI: environmental involvement; MC: media contact; PB: perceived benefit; PC: perceived cost; R: recycling; RA: rule acceptability; RHW: reducing household waste; SN: subjective norm. The ital figures are the square roots of the average variance extracted (AVE) of the corresponding latent construct.

\section{Appendix D}

Factor loading of model 2

\begin{tabular}{|c|c|c|c|c|c|c|c|c|c|c|c|}
\hline & $A T T$ & $E I$ & $M C$ & $P B$ & $P C$ & $R$ & $R A$ & $R H W$ & $S N$ & $C A$ & $C R$ \\
\hline ATT1 & 0.86 & & & & & & & & & 0.84 & 0.90 \\
\hline AAT2 & 0.86 & & & & & & & & & & \\
\hline AAT3 & 0.88 & & & & & & & & & & \\
\hline EI1 & & 0.83 & & & & & & & & 0.86 & 0.91 \\
\hline EA2 & & 0.85 & & & & & & & & & \\
\hline EI3 & & 0.87 & & & & & & & & & \\
\hline EI4 & & 0.81 & & & & & & & & & \\
\hline $\mathrm{MC} 1$ & & & 0.72 & & & & & & & 0.85 & 0.89 \\
\hline MC2 & & & 0.81 & & & & & & & & \\
\hline MC3 & & & 0.83 & & & & & & & & \\
\hline MC4 & & & 0.80 & & & & & & & & \\
\hline MC5 & & & 0.81 & & & & & & & & \\
\hline
\end{tabular}

Notes: ATT: attitude towards waste reduction; EI: environmental involvement;

MC: media contact; PB: perceived benefit; PC: perceived cost; R: recycling;

RA: rule acceptability; RHW: reducing household waste; SN: subjective norm;

CA: Cronbach's alpha; CR: composite reliability. 
Factor loading of model 2 (continued)

\begin{tabular}{|c|c|c|c|c|c|c|c|c|c|c|c|}
\hline & $A T T$ & $E I$ & $M C$ & $P B$ & $P C$ & $R$ & $R A$ & $R H W$ & $S N$ & $C A$ & $C R$ \\
\hline PB1 & & & & 0.90 & & & & & & 0.73 & 0.88 \\
\hline PB2 & & & & 0.87 & & & & & & & \\
\hline $\mathrm{PC} 1$ & & & & & 0.83 & & & & & 0.68 & 0.82 \\
\hline PC2 & & & & & 0.69 & & & & & & \\
\hline PC3 & & & & & 0.79 & & & & & & \\
\hline $\mathrm{R} 2$ & & & & & & 0.90 & & & & 0.71 & 0.87 \\
\hline R4 & & & & & & 0.86 & & & & & \\
\hline RA1 & & & & & & & 0.83 & & & 0.76 & 0.86 \\
\hline RA2 & & & & & & & 0.79 & & & & \\
\hline RA3 & & & & & & & 0.84 & & & & \\
\hline RHW3 & & & & & & & & 0.89 & & 0.84 & 0.90 \\
\hline RHW4 & & & & & & & & 0.86 & & & \\
\hline RHW5 & & & & & & & & 0.82 & & & \\
\hline RHW6 & & & & & & & & 0.72 & & & \\
\hline SN1 & & & & & & & & & 0.86 & 0.80 & 0.88 \\
\hline SN2 & & & & & & & & & 0.86 & & \\
\hline SN3 & & & & & & & & & 0.82 & & \\
\hline
\end{tabular}

Notes: ATT: attitude towards waste reduction; EI: environmental involvement; MC: media contact; PB: perceived benefit; PC: perceived cost; R: recycling; RA: rule acceptability; RHW: reducing household waste; $\mathrm{SN}$ : subjective norm; CA: Cronbach's alpha; CR: composite reliability.

\section{Appendix E}

Latent variable correlations of model 2

\begin{tabular}{lccccccccc}
\hline & $A T T$ & $E I$ & $M C$ & $P B$ & $P C$ & $R$ & $R A$ & $R H W$ & $S N$ \\
\hline ATT & 0.87 & & & & & & & & \\
EI & 0.65 & 0.84 & & & & & & & \\
MC & 0.45 & 0.62 & 0.79 & & & & & & \\
PB & 0.54 & 0.56 & 0.35 & 0.89 & & & & & \\
PC & -0.14 & 0.03 & 0.29 & -0.20 & 0.78 & & & & \\
R & 0.62 & 0.37 & 0.24 & 0.29 & -0.25 & 0.88 & & & \\
RA & 0.54 & 0.52 & 0.33 & 0.57 & -0.25 & 0.37 & 0.82 & & \\
RHW & 0.55 & 0.38 & 0.41 & 0.18 & -0.18 & 0.49 & 0.36 & 0.83 & \\
SN & 0.59 & 0.49 & 0.27 & 0.51 & -0.22 & 0.44 & 0.67 & 0.33 & 0.85 \\
\hline
\end{tabular}

Notes: ATT: attitude towards waste reduction; EI: environmental involvement; MC: media contact; PB: perceived benefit; PC: perceived cost; R: recycling; RA: rule acceptability; RHW: reducing household waste; SN: subjective norm. The ital figures are the square roots of the average variance extracted (AVE) of the corresponding latent construct. 